\title{
Teacher Perception of the School Nurses in Addressing Obesity Among School Children in Kuwait
}

\author{
Alrashidi, M Shahwan-Akl, L Alhaiti, A Aldaihani, M \\ Kuwait Nursing Institute, Public Authority of Training and Education
}

\begin{abstract}
Obesity in children is a global issue and it seems that no country has yet succeeded in addressing this issue. Therefore, investigating the current situation in regard to found new strategies in addressing the overweight and obesity in children by using qualitative research approaches was an important decision made at the beginning of the data collection. This study was conducted to examine the perceptions of school teachers towards the role of the school nurse in tackling obesity among children in Kuwait. Method: Twelve focus group discussions were used to collect the data to obtain in-depth details about the role of school nursing in addressing obesity among school children in sex provinces in Kuwait, The qualitative data were analysed using content analysis. NVivo 10ß qualitative analysis software was used during the process of coding and the development of themes. Result: The focus group findings revealed the following key theme and perceptions among participants: The possible important role of the school nurse is minimised due to limitations of availability (not in every school) and their current roles. focus groups reported that nurses were limited to providing first aid to students, whereas nurses are able to serve in a more proactive, preventative capacity, although not asked to do so. Conclusion: school nurses were underrecognised and not appropriately utilised, as most participants in the second phase did not consider the school nurse as a part of the solution and believed that nurses were employed for emergency needs only. This is not in line with several studies that found that the activities of school nurses, such as delivering health education and taking body weight measurements, is associated with school children having a healthy body weight. Also, school nurses play a major role in advocating for the creation of a healthy environment for school children. Therefore, the current study calls for school nurses to be a part of the solution.
\end{abstract}

Keywords: Obesity, overweight, Kuwait, school children,school nurse, perception.

DOI: $10.7176 / \mathrm{JHMN} / 85-10$

Publication date: January $31^{\text {st }} 2021$

\section{Introduction}

Worldwide, the prevalence of overweight and obesity in children and adults has increased substantially from 857 million to 2.1 billion between 1980 and 2013 (Ng et al., 2014). Kuwait is no exception in relation to these global trends. The findings of sequential studies indicate that overweight and obesity in children and adolescents is becoming more common in Kuwait (El-Bayoumy et al., 2009; Musaiger et al., 2012; Ng et al., 2011; Zaghloul, 2013). As a consequence of this, the MOH in Kuwait has declared that being overweight or obese constitutes a major threat to Kuwaiti society, as it contributes to all chronic diseases and is therefore a major challenge for the health system (Kuwait MOH, 2014a). The failure in combating overweight and obesity over the last 3 decades has contributed to the current worsening situation in the state of Kuwait.

Globally, several health campaigns have been launched by governments to tackle the overweight and obesity epidemic (Kristensen et al., 2014; Kiszko, Martinez, Abrams, \& Elbel, 2014; Taylor et al., 2014). School setting is one of the most targeted places in which to combat obesity in school-aged children (Clarke et al. 2013; ElizondoMontemayor et al., 2013; Lee, Ho, Keung, \& Kwong, 2014), The findings of a systematic review conducted by Verstraeten et al. (2012) indicate that almost 80 of the school-based interventions in six European countries (Germany, England, France, Spain and the Netherlands) reviewed had a positive effect on physical activity and dietary behaviour. Further, Verstraeten et al.'s review also documented a decrease in student's body weight in eight of the 12 studies, due to the effective multicomponent interventions that targeted both diet and physical activity and engaged multiple stakeholders.

Most importantly, the role school nurses have been identified by a number of studies to be an important facilitator in helping students achieve a healthy weight. Mehrley and Leibold (2011) state that nurses in a school setting can cooperate with students, parents, school staff and healthcare clinics to prevent obesity and identify students who may be at risk of health problems as a consequence of obesity. Also, Mehrley and Leibold (2011) state that school nurses can advocate for change both in schools and in the community to promote a healthy lifestyle for school children. Tucker and Lanningham-Foster's (2015) study findings on the effect of school nurses in delivering a healthy message to primary school students indicate a significant increase in children's physical activity. Leibold's (2009) study also documents the positive influence of the school nurse on adolescents' physical activity levels and on children's health in general. Gonzaga et al.'s (2014) integrative review findings indicate that the health promotion programme developed by school nurses contributed to the adoption of a healthy lifestyle by overweight students. 
A cluster-randomised controlled trial conducted by Pbert et al. (2013) evaluated a 2-month intervention, delivered by school nurses, to improve activity, diet and BMI of overweight/obese adolescents. The findings show that the intervention resulted in a number of positive modifications in adolescents' behaviours, including eating breakfast more often and reducing their consumption of sweet beverages and fast food. However, there was no significant difference between the two groups in terms of body weight, calorie intake and physical activity.

In contrast, a randomised controlled trial conducted by Wright, Giger, Norris and Suro (2013) cited the influence of the school nurse on a reduction in children's body weight. These authors evaluated an educational program of physical activity and nutrition classes delivered by nurses for 90 minutes every week for parents and children aged $8-12$ years $(\mathrm{N}=251)$. The results show a statistically significant increase in girls' daily physical activity and boys decreased their sedentary activity. Further, the 12-month follow-up showed there was a decrease in BMI z-scores for both male and female students (Wright, Giger, Norris, \& Suro, 2013). However, this sample population represented the Hispanic/Latino population, thus its generalisability to other ethnic groups may be limited, and there was low retention in attendance, which may affect the findings of the study.

The aforementioned studies indicate that obesity interventions implemented by school nurses lead to positive outcomes. Clarke et al. (2013) indicate that school nurses are concerned about childhood obesity and the consequences associated with obesity and have a desire to do more to reduce the prevalence of obesity in school children. In addition, Lirgg, Gorman and Parish (2014) found that school nurses perceived child obesity as a serious health problem more so than PE teachers and other classroom teachers. Strobel (2014) identified that the majority of nurses agreed that schools should provide an annual screening of students' BMI and share the result with parents.

Strobel (2014) identified that school nurses did not agree that they had adequate time to handle and supervise obesity prevention programs at school. Likewise, Quelly (2014) stated that most school nurses had never or seldom offered counselling to parents regarding a child's body weight concerns. Several factors were found to influence school nurse's perceptions of practices to prevent childhood obesity. Quelly (2014) identified that a lack of time and self-efficacy to involve parents in sensitive discussions about a child's obesity was a major factor. In addition, $\mathrm{Wu}$ and Steele (2011) state that the barriers to nurses addressing obesity include time limitations, self-perceived competence and perceptions of whether addressing children's weight is part of a school nurse's role.

In support, Morrison-Sandberg, Kubik and Johnson (2011) conclude that school nurses provide a height/weight assessment of students, but had stopped offering assessments due to barriers such as staffing limitations, concern that screening was not used for counselling, a lack of surveillance or education and the poor reception of previous weight assessments by parents. Similarly, Steele et al. (2011) identified a lack of institutional support, a lack of knowledge, a lack of resources, a lack of time and personal weight challenges as obstacles to weight-related communications with families.

The available evidence provided in the literature shows the effectiveness of the role of the school nurse on child obesity. There are significant gaps in knowledge about the role of the school nurses in addressing the problem of obesity among children in Kuwait. Therefore, it is essential to clearly define the role of school nurses in relation to obesity prevention and treatment. Findings for this study will contribute to informing the development of new strategies to decrease the obesity rate among children.

\section{Method \\ Study Design}

A qualitative methods were used to explore the role of school nurses toward obesity among school children, in 12 public intermediate schools, The schools were selected from six provinces in Kuwait. Two schools, one boys' school and one girls' school, were randomly targeted in each of the following provinces, namely Al-Asimah, AlFarwaniyah, Al-Ahmadi, Al-Jahrah, Mubarak al-Kabir and Hawalli. An advantage of a focus group is that the interaction between participants' responses and the researcher usually generates more data in relation to the subject of interest (Ary, Jacobs, Sørensen, \& Walker, 2013). Moreover, a focus group provides an environment for the researcher to target a particular group of interest, for example, school teachers, to elicit in-depth information about school environment (Palmer, Larkin, Visser, \& Fadden, 2010).

\section{Sampling}

During the researcher's visits to each school, the significance of the data collection was explained to the school principal and school teachers. The researcher provided the school principal with 12 copies of the consent form along with a letter that explained the purpose of the study to the participants. The school principal distributed the invitation letters that were written in plain language explaining the purpose of the study, along with consent forms inviting the teachers to sign and participate in this study. In addition, the school principals were asked to provide a conference room at a convenient time to conduct the focus group discussions. Two focus group discussions were conducted in each province in the state of Kuwait (one in the boys' school and one in the girls' school). Each focus group lasted 40-60 minutes.

In the focus group discussions the participants were required to provide their responses based on their own 
perceptions.what they understood about the role of the school nurse in tackling this health issue and promoting good health among students. The focus group discussions were audiotaped to help the researcher prepare the transcripts for analysis.

\section{Qualitative data analyses.}

All interviews were audiotaped and were in the Arabic language, because all the participants were Arabic speakers from Kuwait and most did not speak English. The interviews were recorded using an MP3 device in addition to a mobile device in case there was a malfunction in the recording device, hence there was a backup. The data from the interviews was transcribed in Arabic to ensure that no data was missing and then all of this data was translated into English by a professional translation office in Kuwait. The qualitative data was analysed using content analysis The researcher identified, coded and categorised the patterns that emerged from the data (Vaismoradi, Turunen, $\&$ Bondas, 2013). The common statements were used to generate themes that represented the perceptions of the group. These statements were grouped, or clustered, into thematic categories. These thematic categories are presented as part of the findings along with the frequency of occurrence among the focus groups participants. In addition, textual data offered as verbatim examples from the focus groups discussions were included to highlight the key common responses and to clarify these concepts. Relevant data were coded by researcher throughout the document following an inductive process, which allowed for emergent categories. NVivo 10® qualitative analysis software was used during the process of coding and the development of themes. NVivo software provided an organised workspace to conduct the classification and sorting of data and the tracking of the frequency of occurrences across the data sources (Ritchie et al. 2013).

Finally, a comprehensive review and interpretation of the data provided the conclusions of the analysis, which were revealed in the form of several overarching themes representing the perceptions of the individual interviews as a whole (Bazeley \& Jackson, 2013).

\section{Overview of Participants in the Focus Group}

Eighty participants ( 39 males and 41 females) from the 12 schools accepted the invitation to voluntarily take part in this study. Their ages ranged from 25-60 years. The number of participants from each province is presented in Table 1. However, only six of the 12 selected public schools employed a school nurse. As the study ensured that participation was purely voluntary, all school nurses declined to take part in this study because they were employed through private companies that restricted nurses from participating in any research study. The focus group discussions were conducted face-to-face and were audiotaped to help the researcher prepare the transcripts for analysis.

Table 1 Number of Participants from Each Province.

\begin{tabular}{llll}
\hline Provinces & Codes & Schools' & Participants \\
\hline 1-Al-Asimah (capital) & C & Boys'school & 6 participants \\
& CC & Girls' school & 8 participants \\
2-Hawalli & H & Boys'school & 6 participants \\
3-Farwaniyah & HH & Girls' school & 7 participants \\
& F & Boys' school & 8 participants \\
4-Mubarak Al-Kabeer & FF & Girls' school & 8 participants \\
& M & Boys'school & 6 participants \\
5-Al-Ahmadi & MM & Girls' school & 6 participants \\
& A & Boys' school & 7 participants \\
6-AL-Jahra & AA & Girls' school & 6 participants \\
& J & Boys'school & 6 participants \\
& JJ & Girls' school & 6 participants \\
\hline
\end{tabular}

\section{Focus Group Findings}

In discussing the presence of nurses in schools, the majority of participants (10 of 12) described a disparity between schools, where some schools had access to a school nurse, while others did not Also related to school influences on children's health was the presence and function of the school nurse, which formed the sixth sub-category of school influences. The following question was asked: 'Does your school have a school nurse? If so, do they have a role in tackling this health issue? How? Please explain.' In six of the 12 focus groups, the participants discussed having a school nurse present, but felt that the nurses' role was limited to first aid, rather than being used to support improved student health related to obesity. In three of the focus groups, participants discussed the perception that school nurses can play an integral part in the prevention, tracking and treatment of obesity and overweight, but this increased role would depend on the nurses' qualifications and the responsibilities given to them. In contrast, participants in these and other focus groups also described the absence of a school nurse (in total, noted in 6 of 12 
focus groups). Table 2 below provides the variety of responses and associated frequencies. Table 2Presence and Function of School Nurse.

\begin{tabular}{ll}
\hline Response theme & $\begin{array}{l}\text { Frequency among focus groups } \\
\text { (n= 12) }\end{array}$ \\
\hline $\begin{array}{l}\text { Perceived limited role of nurses in schools (first aid only) } \\
\text { School has a school nurse in the limited capacity (does not treat obesity, first aid } \\
\text { only) }\end{array}$ & 12 \\
$\begin{array}{l}\text { Do not have a school nurse } \\
\text { Believe nurse could help prevent, track and treat obesity depending on } \\
\text { qualifications and responsibilities }\end{array}$ & 6 \\
Nurse does not speak Arabic: difficult communication & 2 \\
Ministry should support policies to educate and monitor students & 1 \\
In past had a specified day for medical examinations & 1 \\
Nurses in past were more experienced than now & 1
\end{tabular}

Some schools reportedly had a school nurse, while others did not. Responses of participants described the limited role of the nurse.

He doesn't. Besides the fact that he is Indian and can't speak Arabic, he can only do first aid and follow up on chronic diseases. (Focus Group A. Boys)

Yes, we have a nurse but she doesn't have any role. She should have files and documents for the girls who suffer from obesity or who suffer from any sort of health problem.

No, she can't even speak Arabic. She is unable to communicate with the girls. She only does first aid (Focus Group AA. Girls)

We don't have a nurse in our school. I think that there is no point in having a nurse, because he'd have a limited role with little scope. (Focus Group F. Boys)

Yes, we have a nurse but she doesn't have any role in solving the obesity problem.

Yes, we have a nurse, but she doesn't have a medical scope. Her work is limited in what she can do.

Yes, we have a nurse but she can only do first aid. (Focus Group FF. Girls)

Theme were revealed, highlighting the perceptions of the different focus groups as a whole. conclusions of the analysis of the focus group data emerging main theme indicate poor utilisation of nursing staff in schools, with evidence of an inadequate number of nurses, and the role of the school nurse has been limited to first aid and treatment only, rather than capitalising on their preventative capacity.

\section{Discussion}

A strong theme that emerged from the focus groups demonstrated that school nurses were poorly utilised in Kuwaiti schools. All the participants reported that school nurses were limited to providing first aid rather than capitalising on the potential of nurses to serve an important role in health promotion and disease prevention. Similar findings from a qualitative study conducted in the US indicates that parents and teachers perceived that the role of the school nurse was to administer medications and provide first aid (Maughan \& Adams, 2011).

Similarly, studies on US parents $(\mathrm{N}=369)$ indicated that the majority of parents $(71 \%)$ perceived that the role of the school nurse was to provide emergency care, while $31 \%$ of parents perceived that nurses had a role to play in identifying health problems or performing health screenings (Kirchofer, Telljohann, Price, Dake, \& Ritchie, 2007). Likewise, a study conducted in Greece revealed that $63.9 \%$ of teachers $(\mathrm{N}=144)$ thought that the role of the school nurse was to provide first aid and $36 \%$ believed that the school nurse should provide treatment and health education (Mastrogiannis et al., 2013).

In contrast, several studies disagreed with the results of the current study (Bonde, Bentsen, \& Hindhede, 2014; Wright, Giger, Norris, \& Suro, 2013; Gonzaga et al., 2014; Leibolds, 2009; Mehrley \& Leibold, 2011; Pbert et al., 2013; Tucker \& Lanningham-Foster, 2015; Wright, Giger, Norris, \& Suro 2013). These studies indicate that school nurses can play a critical role in promoting children's health. Kubik and Lee (2013) identified that school nurses are highly skilled members of staff who have been poorly utilised in the fight against obesity.

The findings of a systematic review on the role and influence of nurses in US elementary schools highlighted many significant activities of school nurses that can be described as disease prevention or health promotion, including screening students' vision and BMI, educating students and school staff, and tracking student immunisations (Lineberry \& Ickes, 2014). Pender, Murdaugh and Parsons (2011) conclude that nurses can work with individuals, families and communities to create the optimal conditions for the expression of a high level of wellbeing.

Moreover, evidence provided in the literature indicates that school nurses can contribute to the improvement of adolescents' dietary habits (Pbert et al., 2013), increase children's physical activity (Leibold, 2009; Tucker \& Lanningham-Foster, 2015; Wright et al., 2013), decrease sedentary activity (Wright et al., 2013) and help overweight children and adolescents adopt healthy habits (Gonzaga, Araujo, Cavalcante, Lima, \& Galvao, 2014). 
O'Brien (2012) identified that each point increase in school nurses' activities was associated with a $0.16 \%$ reduction in obesity in school students.

Soto and White (2010) point out that the first step toward obesity intervention starts with screening BMI and sending parents a notification. In fact, several studies' findings indicate that school nurses are screening children's body weight in their daily practice (Krause-Parello \& Samms, 2009; Kubik, Story, \& Davey, 2007; Lineberry \& Ickes, 2014; Stalter, Chaudry, \& Polivka, 2011). Stoddard, Kubik and Skay (2008) stated that school nurses are skilled staff and capable of measuring a child's BMI in a reliable and private manner. Likewise, Hendershot, Telljohann, Price, Dake and Mosca's $(2008)$ study on school nurses $(\mathrm{N}=2,629)$ found that $81 \%$ of nurses believed they should set a plan to address overweight in children, and up to $67 \%$ of the nurses believed they should measure BMI and send this information home.

Some participants in the current study suggest that school nurses can play an essential role in the prevention of disease, but this role would depend on the nurses' qualifications and responsibilities. It is true that the literature indicates that the school nurses perceived several barriers to addressing obesity, including a lack of knowledge, a lack of resources, time and support, as well as personal weight challenges (Steele et al., 2011). In addition, a lack of privacy, high workloads and a lack of policy support were seen as key barriers to body weight assessment (Stalter, Chaudry, \& Polivka, 2011). Moyers, Bugle and Jackson (2005) found that school nurses perceived numerous barriers to taking a more active role in tackling childhood obesity, including a low level of competence and difficulty in providing counselling and a lack of parental support.

Quelly (2014) summarised that school nurses need further education, policy support and professional mentoring to take part in childhood obesity intervention. Moreover, Melin and Lenner (2009) found that trained school nurses with sufficient knowledge working in a collaborative team were more effective in tackling overweight and obesity in their schools.

Another important barrier noted by two focus groups in the current study was a lack of communication. One participant commented that nurses do not speak Arabic, and that they faced difficulties in communicating with nurses. This is common in the Arabic world (Al-Khathami, Kojan, Aljumah, Alqahtani, \& Alrwaili, 2010; AlJarallah, Moussa, Hakeem, \& Al-Khanfar, 2009; Almutairi, McCarthy, \& Gardner, 2014), since the majority of nurses are foreign and they are not Arabic speakers. Indeed, barriers to communication are considered a serious matter that needs to be addressed to provide a high quality of service and ensure client satisfaction.

Divi, Koss, Schmaltz and Loeb (2007) mentioned that a language barrier can seriously harm patient safetythis harm ranging from moderate to death. Therefore, health providers are often obligated to provide an interpreter service (Green et al., 2005; Suliman \& Tadros, 2011). For instance, Suliman, and Tadros (2011) stated that nursing administrations in Saudi Arabia have addressed the language barrier by appointing bilingual staff as interpreters to facilitate effective communication between patients and nurses.

Finally, it was noted in the present study that there are shortages of school nurses. Not surprisingly, this is a global issue and has been reported in many countries, for example, in China (Yun, Jie, \& Anli 2010), in India (Saeed, 2010), in Iran (Zarea, Negarandeh, Dehghan-Nayeri, \& Rezaei-Adaryani, 2009) and in Saudi (Almalki, FitzGerald, \& Clark, 2011). Chan, Tam, Lung, Wong and Chau (2013) attribute the shortage of nurses to individual factors, including job satisfaction, demographic factors, burnout and organisational factors such as work commitment, environment, social support, culture and work demands.

Al-Kandari and Lew (2005) attribute the shortage of nurses in Kuwait to the high turnover rate among foreign nurses, low production of indigenous nurses and the expansion of health care services. In contrast, Almalki, FitzGerald and Clark (2011) point out that the mass media in Saudi Arabia should engage in promoting nursing as a career, and the education sector should support students financially and reduce the length of nursing training to 3 years, rather than 5 years, to encourage Saudi youth to study nursing as a specialty. Similarly, Chan, Tam, Lung, Wong and Chau (2013) suggest that enhancing the work environment and increasing nurses' external rewards is needed to address the nursing shortage.

In conclusion, the findings of the current study indicate that the role of school nurses in Kuwait is underrecognised and, not surprisingly, the majority of school nurses in Kuwait are employed from private companies who look for profit rather than the quality of work. The findings of this study show that most of the participants agreed that school nurses do not play a role in either promoting children's health or the prevention of disease. However, this is not in line with the evidence provided in the literature. It seems that the shortage of nurses, language barriers and qualifications result in the underestimation of the role of school nurses.

\section{Recommendation}

The literature review provided evidence to indicate that school nurses can play an important role in designing and implementing intervention strategies to prevent obesity and promote healthy lifestyles to students (Gonzaga, Araujo, Cavalcante, Lima, \& Galvao, 2014; Kubik, Story, \& Davey, 2007; O’Brien, 2012). Therefore, it was felt that it was important to produce particular recommendations for school nurses to help nurses take part in the obesity prevention program. It is recommended that the $\mathrm{MOH}$ and Ministry of Education should cooperate with nurses to 
address all the barriers currently facing school nurses, such as a lack of knowledge, a lack of time, a lack of resources and a lack of support. For instance, the ME has the responsibility for the education of nurses in Kuwait, so they should rethink this and provide a comprehensive education program to help nurses be more effective in terms of health education. Also, they should ensure that school clinics are adequately equipped and resourced with the necessary materials to help nurses engage in child obesity prevention programs.

Another recommendation is for the $\mathrm{ME}$ to recruit school nurses according to their experience and qualifications. This recommendation will ensure that nurses are able to effectively perform their duties in relation to obesity prevention in school children. In addition, the $\mathrm{MOH}$ has a role to play in helping nurses improve their skills and knowledge by providing intensive programs that will restore nurses' confidence in being involved in primary, secondary and tertiary intervention. The $\mathrm{MOH}$ also needs to build relationships between the healthcare providers, parents and school nurses to identify children who are at risk of overweight and need intervention for follow-up.

\section{Conflict of interest}

The authors declare that they have no conflict of interest.

\section{Acknowledgments}

I would like to express my deep gratitude to my supervisors, starting with Associate Professor Lina Shahwan for her expert supervision. Also, my sincere and deepest thanks to my supervisor, Dr Jennifer James, for playing an important role in this study and for always being optimistic that I also extend my special thanks to Associate Professor Phillip Maude, and I am very grateful to Dr Linda Jones for her amazing support and guidance. Extend my thanks and gratitude to the government of the state of Kuwait for supporting me and granting me scholarship.

\section{References}

Al-Kandari, F. H., \& Lew, I. (2005). Kuwaiti high school students' perceptions of nursing as a profession: Implications for nursing education and practice. Journal of Nursing Education, 44(12), 533-40.

Al-Khathami, A. M., Kojan, S. W., Aljumah, M. A., Alqahtani, H., \& Alrwaili, H. (2010). The effect of nursepatient language barrier on patients' satisfaction. Saudi Medical Journal, 31(12), 1355-1358.

Al-Jarallah, K. F., Moussa, M. A. A., Hakeem, S. K., \& Al-Khanfar, F. K. (2009). The nursing workforce in Kuwait to the year 2020. International Nursing Review, 56(1), 65-72.

Almalki, M., FitzGerald, G., \& Clark, M. (2011). The nursing profession in Saudi Arabia: An overview. International Nursing Review, 58(3), 304-311.

Almutairi, A. F., McCarthy, A., \& Gardner, G. E. (2014). Understanding cultural competence in a multicultural rursing workforce registered nurses' experience in Saudi Arabia. Journal of Transcultural Nursing, 1043659614523992.

Ary, D., Jacobs, L., Sorensen, C., \& Walker, D. (2013). Introduction to research in education. Cengage Learning. $\begin{array}{llll}\text { Retrieved } & 20 & \text { January } & 2018\end{array}$ from https://books.google.com.au/books?hl=en\&lr=\&id=WSQLAAAAQBAJ\&oi=fnd\&pg=PR7\&dq=Introductio $\mathrm{n}+$ to + research+in+education.

Bazeley, P., \& Jackson, K. (Eds.). (2013). Qualitative data analysis with NVivo. Sage Publications Limited. $\begin{array}{llll}\text { Retrieved } & 10 & \text { October } & 2017\end{array}$ https://books.google.com.au/books?hl=en\&lr=\&id=Px8cJ3suqccC\&oi=fnd\&pg=PP2\&dq=Qualitative+data + analysis+with+NVivo.

Bonde, A. H., Bentsen, P., \& Hindhede, A. L. (2014). School nurses' experiences with motivational interviewing for preventing childhood obesity. Journal of School Nursing, 30(6), 448-455.Boutelle, K. N., Cafri, G., \& Crow, S. J. (2012). Parent predictors of child weight change in family based behavioral obesity treatment. Obesity, 20(7), 1539-1543.

Chan, C. M. S., \& Wang, W. C. (2013). Quality of life in overweight and obese young Chinese children: A mixedmethod study. Health and Quality of Life Outcomes, 11(1), 33.

Chan, Z. C., Tam, W. S., Lung, M. K., Wong, W. Y., \& Chau, C. W. (2013). A systematic literature review of nurse shortage and the intention to leave. Journal of Nursing Management, 21(4), 605-613.

Clarke, J., Fletcher, B., Lancashire, E., Pallan, M., \& Adab, P. (2013). The views of stakeholders on the role of the primary school in preventing childhood obesity: A qualitative systematic review. Obesity Reviews, 14(12), 975-988.

Clarke, J., Fletcher, B., Lancashire, E., Pallan, M., \& Adab, P. (2013). The views of stakeholders on the role of the primary school in preventing childhood obesity: A qualitative systematic review. Obesity Reviews, 14(12), 975-988.

Divi, C., Koss, R. G., Schmaltz, S. P., \& Loeb, J. M. (2007). Language proficiency and adverse events in US hospitals: A pilot study. International Journal for Quality in Health Care, 19(2), 60-67. 
El-Bayoumy, I., Shady, I., \& Lotfy, H. (2009). Prevalence of obesity among adolescents (10 to 14 years) in Kuwait. Asia-Pacific Journal of Public Health, 3(10), 117-1010.

Elizondo-Montemayor, L., Gutierrez, N. G., Moreno, D. M., Martinez, U., Tamargo, D., \& Trevino, M. (2013). School-based individualised lifestyle intervention decreases obesity and the metabolic syndrome in Mexican children. Journal of Human Nutrition and Dietetics, 26(1), 82-89.

Gonzaga, N. C., Araujo, T. L. D., Cavalcante, T. F., Lima, F. E. T., \& Galvao, M. T. G. (2014). Nursing: Promoting the health of overweight children and adolescents in the school context. Revista da Escola de Enfermagem da USP, 48(1), 153-161.

Green, A. R., Ngo-Metzger, Q., Legedza, A. T., Massagli, M. P., Phillips, R. S., \& Iezzoni, L. I. (2005). Interpreter services, language concordance, and health care quality. Journal of General Internal Medicine, 20(11), 10501056.

Hendershot, C., Telljohann, S. K., Price, J. H., Dake, J. A., \& Mosca, N. W. (2008). Elementary school nurses' perceptions and practices regarding body mass index measurement in school children. Journal of School Nursing, 24(5), 298-309.

Kirchofer, G., Telljohann, S. K., Price, J. H., Dake, J. A., \& Ritchie, M. (2007). Elementary school parents'/guardians' perceptions of school health service personnel and the services they provide. Journal of School Health, 77(9), 607-614.

Kiszko, K. M., Martinez, O. D., Abrams, C., \& Elbel, B. (2014). The influence of calorie labeling on food orders and consumption: A review of the literature. Journal of Community Health, 39(6), 1248-1269.

Krause-Parello, C. A., \& Samms, K. (2009). The US model: The role of school nurses in New Jersey. British Journal of School Nursing, 4(6), 287-292.

Kristensen, A. H., Flottemesch, T. J., Maciosek, M. V., Jenson, J., Barclay, G., Ashe, M., . . Brownson, R. C. (2014). Reducing childhood obesity through US federal policy: A microsimulation analysis. American Journal of Preventive Medicine, 47(5), 604-612.

Kubik, M. Y., \& Lee, J. (2013). Parent interest in a school-based, school nurse-led weight management program. Journal of School Nursing. doi:1059840513485091

Kubik, M. Y., Story, M., \& Davey, C. (2007). Obesity prevention in schools: Current role and future practice of school nurses. Preventive Medicine, 44(6), 504-507.

Kuwait Ministry of Health. (2014). Obesity in Kuwait. Retrieved 10 March 2014 from http://seifnews.com/news/kuwait/29066

Lee, A., Ho, M., Keung, V. M., \& Kwong, A. C. (2014). Childhood obesity management shifting from health care system to school system: Intervention study of school-based weight management programme. BMC Public Health, 14(1), 14-1128.

Leibold, N. (2009). The effect of a school nurse led education intervention on blood pressure and physical activity levels in adolescents (Doctoral dissertation, College of Saint Mary).

Leibold, N. (2009). The effect of a school nurse led education intervention on blood pressure and physical activity levels in adolescents (Doctoral dissertation, College of Saint Mary). Retrieved 15 August 2018 from http://www.csm.edu/wfdata/files/Academics/Library/InstitutionalRepository/13.pdf

Lineberry, M. J., \& Ickes, M. J. (2014). The role and impact of nurses in American elementary schools: A systematic review of the research. Journal of School Nursing. doi: 1059840514540940

Lirgg, C., Gorman, D., \& Parish, A. (2014). School personnel perceptions of childhood obesity. Research Quarterly for Exercise and Sport, 85(Suppl. 1), A78-A79.

Mastrogiannis, D., Deltsidou, A., Noula, M., Poulaka, M. A., Gesouli-Voltyraki, E., Fouka, G., ... Mantzorou, M. (2013). Exploring educationalists' views on the need for school nurses in secondary schools in Greece. British Journal of School Nursing, 8(6), 303-307.

Maughan, E., \& Adams, R. (2011). Educators' and parents' perception of what school nurses do the influence of school nurse/student ratios. Journal of School Nursing, 27(5), 355-363.

Mehrley, M., \& Leibold, N. (2011). Overweight and obesity in youth in schools: The role of the school nurse. Position statement. Revised. National Association of School Nurses (NJ1).

Melin, A., \& Lenner, R. A. (2009). Prevention of further weight gain in overweight school children, a pilot study. Scandinavian Journal of Caring Sciences, 23(3), 498-505.

Morrison-Sandberg, L. F., Kubik, M. Y., \& Johnson, K. E. (2011). Obesity prevention practices of elementary school nurses in Minnesota: Findings from interviews with licensed school nurses. Journal of School Nursing, 27(1), 13-21.

Moyers, P., Bugle, L., \& Jackson, E. (2005). Perceptions of school nurses regarding obesity in school-age children. Journal of School Nursing, 21(2), 86-93.

Musaiger, A. O., Zaal, A. B., \& D’Souza, R. (2012). Body weight perception among adolescents in Dubai, United Arab Emirates. Nutricion Hospitalaria, 27(6), 1966-72.

Ng, M., Fleming, T., Robinson, M., Thomson, B., Graetz, N., Margono, C., \& Gupta, R. (2014). Global, regional, 
and national prevalence of overweight and obesity in children and adults during 1980-2013: A systematic analysis for the global burden of disease study 2013. The Lancet, 384(9945), 766-781.

Ng, S. W., Zaghloul, S., Ali, H. I., Harrison, G., \& Popkin, B. M. (2011). The prevalence and trends of overweight, obesity and nutrition-related non-communicable diseases in the Arabian Gulf States. Obesity Reviews, 12(1), $1-13$.

O’Brien, M. J. F. (2012). The associations of the level of school wellness policy implementation and school nurse activities to weight status of school children in Massachusetts (Doctoral dissertation, University of

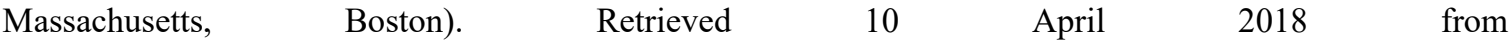
http://scholarworks.umb.edu/doctoral dissertations/92/

Palmer, M., Larkin, M., de Visser, R., \& Fadden, G. (2010). Developing an interpretative phenomenological approach to focus group data. Qualitative Research in Psychology, 7(2), 99-121.

Pbert, L., Druker, S., Gapinski, M. A., Gellar, L., Magner, R., Reed, G., . . Osganian, S. (2013). A school nursedelivered intervention for overweight and obese adolescents. Journal of School Health, 83(3), 182-193.

Pender, N. J., Murdaugh, C. L., \& Parsons, M. A. (2011). Health promotion in nursing practice (6th ed.). Boston, MA: Pearson.

Quelly, S. B. (2014). Influence of perceptions on school nurse practices to prevent childhood obesity. Journal of School Nursing, 30(4), 292-302

Ritchie, J., Lewis, J., Nicholls, C. M., \& Ormston, R. (Eds.). (2013). Qualitative research practice: A guide for social science students and researchers. Sage. Retrieved 2 July 2017 from https://books.google.com.au/books?hl=en\&lr=\&id=EQSIAwAAQBAJ\&oi=fnd\&pg=PP1\&dq=).+Qualitativ e+research+practice:+A+guide+for+social+science+students+and+researchers.\&ots=1ZUPjpUs0M\&sig=zH GM

Saeed, A. (2010). Wanted: 2.4 million nurses, and that's just in India. Bulletin of the World Health Organization, $88(5), 327-328$.

Soto, C., \& White, J. H. (2010). School health initiatives and childhood obesity: BMI screening and reporting. Policy, Politics, \& Nursing Practice, 11(2), 108-114.

Stalter, A. M., Chaudry, R. V., \& Polivka, B. J. (2011). Regional differences as barriers to body mass index screening described by Ohio school nurses. Journal of School Health, 81(8), 437-448.

Steele, R. G., Wu, Y. P., Jensen, C. D., Pankey, S., Davis, A. M., \& Aylward, B. S. (2011). School nurses' perceived barriers to discussing weight with children and their families: A qualitative approach. Journal of School Health, 81(3), 128-137.

Stoddard, S. A., Kubik, M. Y., \& Skay, C. (2008). Is school-based height and weight screening of elementary students private and reliable? Journal of School Nursing, 24(1), 43-48.

Strobel, M. S. (2014). An evaluation of Northwest Arkansas elementary school nurses' perceptions of their role in the management and prevention of obesity (Doctoral dissertation, University of Arkansas).

Suliman, W. A., \& Tadros, A. (2011). Nursing students coping with English as a foreign language medium of instruction. Nurse Education Today, 31(4), 402-407.

Taylor, A. L., Parento, E. W., \& Schmidt, L. (2014). The increasing weight of regulation: Countries combat the global obesity epidemic. Indiana Law Journal, 90.

Tucker, S., \& Lanningham-Foster, L. M. (2015). Nurse-led school-based child obesity prevention. Journal of School Nursing. doi: 1059840515574002

Vaismoradi, M., Turunen, H., \& Bondas, T. (2013). Content analysis and thematic analysis: Implications for conducting a qualitative descriptive study. Nursing \& Health Sciences, 15(3), 398-405. doi:10.1111/nhs. 12048

Verstraeten, R., Roberfroid, D., Lachat, C., Leroy, J. L., Holdsworth, M., Maes, L., \& Kolsteren, P. W. (2012). Effectiveness of preventive school-based obesity interventions in low- and middle-income countries: A systematic review. American Journal of Clinical Nutrition, 96(2), 035-378.

Wright, K., Giger, J. N., Norris, K., \& Suro, Z. (2013). Impact of a nurse-directed, coordinated school health program to enhance physical activity behaviors and reduce body mass index among minority children: A parallel-group, randomized control trial. International Journal of Nursing Studies, 50(6), 727-737.

Wu, Y. P., \& Steele, R. G. (2011). The development and evaluation of a measure assessing school nurses' perceived barriers to addressing pediatric obesity. Journal of School Nursing, 27(5), 372-379.

Yun, H., Jie, S., \& Anli, J. (2010). Nursing shortage in China: State, causes, and strategy. Nursing Outlook, 58(3), $122-128$.

Zaghloul, S., Al-Hooti, S. N., Al-Hamad, N., Al-Zenki, S., Alomirah, H., Alayan, I., ... \& Jackson, R. T. (2013). Evidence for nutrition transition in Kuwait: over-consumption of macronutrients and obesity. Public Health Nutrition, 16(04), 596-607.

Zarea, K., Negarandeh, R., Dehghan-Nayeri, N., \& Rezaei-Adaryani, M. (2009). Nursing staff shortages and job satisfaction in Iran: Issues and challenges. Nursing \& Health Sciences, 11(3), 326-331. 